\title{
Hypocrea stromatica sp. nov. teleomorfo de Trichoderma stromaticum
}

\author{
José L. Bezerra ${ }^{1}$, João C. B. Costa ${ }^{1}$, Cleber N. Bastos ${ }^{2}$ \& Fábio G. Faleiro ${ }^{3}$ \\ ${ }^{1}$ CEPLAC/CEPEC, Seção de Fitopatologia, Cx. Postal 07, CEP 45600-970, Itabuna, Bahia, Brasil; ${ }^{2}$ CEPLAC/SUPOR/ERJOH, \\ Cx. Postal 46, CEP 67105-970 Belém, PA, Brasil; ; Embrapa Cerrados, Cx. Postal 08223, CEP 73301-970 Planaltina, DF, \\ Brasil, e-mail: jlbezerra@cepec.gov.br
}

(Aceito para publicação em 10/03/2003)

Autor para correspondência: José Luiz Bezerra

BEZERRA, J.L., COSTA, J.C.B., BASTOS, C.N. \& FALEIRO, F.G. Hypocrea stromatica sp. nov. teleomorfo de Trichoderma stromaticum. Fitopatologia Brasileira 28:408-412. 2003.

\section{RESUMO}

Trichoderma stromaticum é um fungo antagonista a Crinipellis perniciosa, agente causal da vassoura-de-bruxa do cacaueiro (Theobroma cacao). Estromas periteciais de Hypocrea sp. formaram-se sobre a superfície de frutos mumificados e vassouras secas de cacaueiros em áreas onde $T$. stromaticum tinha sido pulverizado, experimentalmente, no controle biológico de $C$. perniciosa. Ascósporos obtidos dos estromas de Hypocrea sp. originaram colônias idênticas às de T. stromaticum. DNA genômico de colônias provenientes de ascósporos desta Hypocrea sp., de conídios de T. stromaticum e de Fusarium sp. (controle negativo) foi extraído e amplificado com oito "primers" decâmeros para obtenção de marcadores RAPD. Observaram-se similaridades genéticas de 0,82 a 0,96 entre os isolados ascospóricos e conidiais com base nos marcadores RAPD e de 0,06 a 0,09 entre estes e o isolado de Fusarium sp. O teleomorfo de T. stromaticum é denominado H. stromatica Bezerra, Costa \& Bastos sp. nov.

Palavras-chave adicionais: cacaueiro, Theobroma cacao, taxonomia de fungos, caracterização molecular, morfologia de fungos.

\section{ABSTRACT}

Hypocrea stromatica sp. nov., the teleomorph of Trichoderma stromaticum

Trichoderma stromaticum is a fungal antagonist to Crinipellis perniciosa, causal agent of cacao (Theobroma cacao)witches' broom disease. Peritecial stromata of a Hypocrea species developed on the surface of mummified pods and dried brooms of cacao, in areas where $T$. stromaticum had been applied, experimentally, as a biological agent to control C. perniciosa. Ascospores obtained from this Hypocrea sp. gave rise to colonies identical to those of $T$. stromaticum. Genomic DNA from cultures developed from ascospores of this Hypocrea sp., conidia of $T$. stromaticum and Fusarium sp. (negative control) was extracted and amplified with eight decamer primers to obtain RAPD markers. Genetic similarities from 0.82 to 0.96 were observed between ascosporic and conidial isolates based on RAPD markers, and from 0.06 to 0.09 between these and the Fusarim sp. isolate. The teleomorph of T. stromaticum is, thus, proposed as H. stromatica Bezerra, Costa \& Bastos sp. nov.

\section{INTRODUÇÃO}

Trichoderma stromaticum Samuels \& PardoSchultheiss, espécie de fungo antagonista a Crinipellis perniciosa (Stahel) Singer, tem sido usada no controle biológico da vassoura-de-bruxa do cacaueiro (Theobroma cacao L.) (Costa \& Bastos, 2001). A espécie foi descrita por Samuels et al. (2000), a partir de culturas levadas da Bahia e provenientes dos estados do Pará e Rondônia. A existência do seu teleomorfo não é mencionada na descrição original. O gênero Trichoderma é considerado anamorfo de Hypocrea Fr. (Chaverri et al., 2000). O teleomorfo de T. virens (Miller, Giddens \& Foster) v.Arx foi recentemente descrito (Chaverri et al., 2001) como Hypocrea virens Chaverri, Samuels \& Stewart.

Estromas de Hypocrea sp. em áreas pulverizadas com $T$. stromaticum começaram a ser coletados em 1998, no Centro de Pesquisas do Cacau, sobre frutos mumificados de cacau, cacaudo-peru (Theobroma bicolor Humb. \& Bonpl.) e cupuaçu ( $T$. grandiflorum (Wild ex Spreng) Schum). Posteriormente, estromas similares passaram a ser observado sobre vassouras secas de cacau, em vários municípios da região cacaueira da Bahia.

O objetivo deste trabalho foi demonstrar a conexão entre T. stromaticum e a Hypocrea sp., ou seja, o seu teleomorfo, com base em dados morfológicos e moleculares e descrevê-lo como uma nova espécie do gênero, elucidando o ciclo vital deste fungo, de grande relevância para o controle biológico de C. perniciosa no cacaueiro.

\section{MATERIAL EMÉTODOS}

Isolados de Hypocrea sp. foram obtidos a partir de vassouras secas de cacaueiros, na Bahia, da seguinte forma: estromas ascígeros foram desinfestados com álcool a 70\%, hipoclorito de sódio a $1 \%$, ambos durante $30 \mathrm{~s}$. Em seguida foram lavados quatro vezes, por $30 \mathrm{~s}$, em água destilada, esterilizada e colocados em placas de Petri contendo agarágua ou meio de batata-dextrose-agar (BDA) acidificado. As placas foram incubadas a $25 \pm 2^{\circ} \mathrm{C}$, no escuro, e examinadas na lupa, a cada $12 \mathrm{~h}$, para observação de ascósporos germinados. Após 24 h, as pequenas colônias desenvolvidas a partir dos 
ascósporos ejetados sobre a superfície do meio foram repicadas para meio BDA e estudadas quanto ao aspecto e cor da colônia e esporulação do patógeno desenvolvidas à mesma temperatura usada no isolamento. O estudo morfológico e biométrico dos estádios teleomórfico e anamórfico foi realizado utilizando-se raspagens e cortes histológicos manuais das estruturas de valor taxonômico. Usou-se lactofenol de Amann, com e sem adição de azul-de-algodão, no preparo das lâminas para observações microscópicas.

A análise molecular foi feita a partir de DNA genômico de duas colônias provenientes de ascósporos de Hypocrea sp., duas de conídios de T. stromaticum e uma de Fusarium sp. (controle negativo). A extração do DNA foi realizada a partir de aproximadamente $200 \mathrm{mg}$ de massa micelial de cada colônia, utilizando-se o método sodium dodecyl sulphate (SDS). O micélio foi macerado em cadinho de porcelana em contato com $\mathrm{N}_{2}$ líquido. Após, o macerado foi colocado em um tubo plástico de $1,5 \mathrm{ml}$, ao qual foi adicionado $700 \mu \mathrm{l}$ de tampão de lise constituído por Tris-HCl $200 \mathrm{mM}$, pH 8,0, EDTA 25 $\mathrm{mM}, \mathrm{SDS} 1 \%, \mathrm{NaCl} 250 \mathrm{mM}$ e 2-mercaptoetanol 1\%. O macerado foi misturado ao tampão de lise e os tubos foram mantidos em banho-maria $\left(70{ }^{\circ} \mathrm{C}\right)$ por uma hora, sendo agitados a cada $10 \mathrm{~min}$. Após a incubação, foi realizada a desproteinização, adicionando-se $600 \mu 1$ de clorofórmio-álcool isoamílico $(24: 1 \mathrm{v} / \mathrm{v})$. Em seguida, as amostras foram agitadas por $10 \mathrm{~min}$, por suaves inversões, e centrifugadas a $4^{\circ} \mathrm{C}, 18.845$ rpm, por $10 \mathrm{~min}$. O sobrenadante de cada amostra foi transferido para tubos de $1,5 \mathrm{ml}$ limpos e o processo de desproteinização foi repetido.

Para a precipitação do DNA, foi adicionado ao sobrenadante final, 1/10 do seu volume de acetato de sódio 3 $\mathrm{M}, \mathrm{pH}$ 5,2 e 2/3 de isopropanol gelado. Os tubos foram mantidos a $-20{ }^{\circ} \mathrm{C}$ por $2 \mathrm{~h}$ e, a seguir, centrifugados como anteriormente. O sobrenadante foi descartado e o precipitado foi lavado duas vezes com etanol $70 \%(\mathrm{v} / \mathrm{v})$ e seco à temperatura ambiente. Posteriormente, os ácidos nucléicos totais foram ressuspendidos em $150 \mu \mathrm{l}$ de água contendo RNAse na concentração de $40 \mu \mathrm{g} / \mathrm{ml}$ e colocados em banho-maria a $37^{\circ} \mathrm{C}$ para a completa ressuspensão. Após esse período, o DNA foi novamente precipitado, centrifugado e ressuspendido em $150 \mu 1$ de água, como já descrito. A quantidade do DNA foi estimada por espectrofotometria a $260 \mathrm{~nm}$ (Sambrook et al., 1989) e posteriormente diluída para $10 \mathrm{ng} / \mu \mathrm{l}$.

Amostras de DNA de cada isolado foram amplificadas pela técnica de RAPD (Random Amplified Polymorphic DNA). As reações de amplificação foram feitas em um volume total de $25 \mu$ l, contendo Tris- $\mathrm{HCl} 10 \mathrm{mM}$ (pH 8,3), $\mathrm{KCl} 50 \mathrm{mM}, \mathrm{MgCl}_{2} 2$ $\mathrm{mM}, 100 \mu \mathrm{M}$ de cada um dos desoxinucleotídios (dATP, dTTP, dGTP e dCTP), 0,4 $\mu \mathrm{M}$ de um "primer" (Operon Technologies Inc., Alameda, CA, EUA), uma unidade da enzima Taq polimerase e, aproximadamente, $30 \mathrm{ng}$ de DNA. Foram utilizados os "primers" decâmeros OPA7, OPL5, OPL8, OPL16, OPM12, OPN16, OPO6 e OPO12 (Operon Technologies Inc., Alameda, CA, EUA) para obtenção dos marcadores RAPD. As amplificações foram efetuadas em termociclador, programado para 40 ciclos, cada um constituído pela seguinte sequiência:
15 s a $94^{\circ} \mathrm{C}, 30$ s a $35^{\circ} \mathrm{Ce} 90$ s a $72^{\circ} \mathrm{C}$. Após os 40 ciclos, foi feita uma etapa de extensão final de $7 \mathrm{~min}$ a $72^{\circ} \mathrm{C}$ e finalmente, a temperatura foi reduzida para $4^{\circ} \mathrm{C}$. Após a amplificação, foram adicionados, a cada amostra, $3 \mu \mathrm{l}$ de uma mistura de azul de bromofenol $(0,25 \%)$, glicerol $(60 \%)$ e água $(39,75 \%)$. Essas amostras foram aplicadas em gel de agarose $(1,2 \%)$, submerso em tampão TBE (Tris-Borato 90 mM, EDTA 1 mM). A separação eletroforética foi de, aproximadamente, 4 h, a 90 volts. Ao término da corrida, os géis foram corados com brometo de etídio e fotografados sob luz ultravioleta.

Os marcadores RAPD gerados foram convertidos em uma matriz de dados binários, a partir da qual foram calculadas distâncias genéticas baseadas no complemento do coeficiente de similaridade (D) de Nei \& Li (1979), utilizando-se o Programa Genes (Cruz, 1997). Com base na matriz de distâncias genéticas, foi realizada uma análise de agrupamento por meio de dendrograma, utilizando-se o método do centróide como critério de agrupamento.

\section{RESULTADOS}

\section{Características culturais}

Culturas obtidas de ascósporos originaram colônias típicas de T. stromaticum. Todos os isolados desenvolveramse bem em temperaturas entre 25 e $28^{\circ} \mathrm{C}$. As características culturais dos isolados do teleomorfo e do anamorfo foram praticamente idênticas. Não se observou diferença com relação à taxa de crescimento das colônias desses isolados. Aos sete dias de crescimento em BDA, à temperatura de aproximadamente $25^{\circ} \mathrm{C}$, e luz ambiente, as colônias apresentaram micélio denso, esbranquiçado, rasteiro, formando conídios mais concentrados próximo à margem das colônias.

\section{Análise molecular}

Os oito primers decâmeros geraram um total de 73 marcadores RAPD, sendo a média de 9,1 marcas por primer. Observaram-se similaridades genéticas de 0,82 a 0,96 entre os isolados ascospóricos e conidiais com base nos marcadores RAPD e de 0,06 a 0,09 entre estes e o isolado de Fusarium sp. (Tabela 1). A análise de agrupamento mostrou que os isolados de $T$. stromaticum e de Hypocrea ficaram no mesmo grupo, e que tais isolados foram geneticamente distantes do isolado de Fusarium sp. (Figura 1).

\section{Taxonomia}

Os dados morfológicos e moleculares permitiram a proposição da seguinte nova espécie de Hypocrea:

Hypocrea stromatica Bezerra, Costa et Bastos, sp. nov. (Figura 2).

Stromata solitaria, ochracea vel pallide-brunnea, 0,51,3 mm. Asci cylindrici, 78-93 x 4,3-5,0 $\mu \mathrm{m}$, apice incrassato praediti. Ascosporae bicellulares, ad septum disarticulatae, ellipsoideae, 9,7-11,4 x 3,5-4,0 $\mu \mathrm{m}$, parte distali, 4,5-5,7 x 3,5-4,0 $\mu \mathrm{m}$, parte proximali, 4,0-5,7x3,4-4,0 $\mu \mathrm{m}$, hyalinae, verruculosae. HOLOTYPUS: HERBÁRIOCEPEC 94.140.

Anamorfo. - Trichoderma stromaticum Samuels \& 
Pardo-Schultheiss, Mycological Research 104(6):760-764. 2000.

Estromas dispersos, pulvinados, de cor amarelada a castanho-alaranjada, $\mathrm{KOH}$-, de contorno quase circular, 0,51,3 mm de diâmetro, base constricta, superfície áspera devido às protuberâncias ostiolares, com cerca de 15 a 20 peritécios por estroma. Parede do estroma pseudoparenquimática, de textura angular, 35,8-57,2 $\mu \mathrm{m}$ de espessura, formada de células subhialinas, 7,2-18,6 x 5,7-11,4 $\mu \mathrm{m}$, com paredes 0.57-0,86 $\mu \mathrm{m}$ de espessura. Peritécios subglobosos 114-160 $\mu \mathrm{m}$ de altura e 114-143 $\mu \mathrm{m}$ de largura, com ostíolo papilado, 86-93 $\mu \mathrm{m}$ de altura e 33-57 $\mu \mathrm{m}$ de largura, canal ostiolar 14,3-17,0 $\mu \mathrm{m}$ de diâmetro. Ascos cilíndricos, octospóricos, 78,0-93,0 x 4,3-5,0 $\mu \mathrm{m}$, levemente espessados no ápice. Ascósporos oblongos a elipsóides, bicelulares, fortemente constritos no septo, de paredes ásperas, 9,7-11,4 x 3,5-4,0 $\mu \mathrm{m}$, separando-se em duas células desiguais hialinas; célula apical subglobosa 4,5-5,7 x 3,5-4,0 $\mu$ m e célula basal levemente atenuada 4,0-5,7 x 3,4-4,0 $\mu \mathrm{m}$. Conídios hialinos, tornando-se amarelados, castanho-claros, verdes ou amareloesverdeados em massa. Alguns isolados esporulam formando "ilhas" de conídios sobre toda a superfície do meio. Os conídios desenvolvem-se abundantemente na superfície de pústulas (estromas) conidiais pulvinadas a hemisféricas, $1-3 \mathrm{~mm}$ de diâmetro. Fiálides agrupadas, subglobosas a ampuliformes, constritas no ápice, 5-7 $\mu \mathrm{m}$ de comprimento e 3-4 $\mu \mathrm{m}$ de largura na região mediana. Setas aciculares de ápice estéril ou fértil, até $70 \mu \mathrm{m}$ de comprimento e cerca de $6 \mu \mathrm{m}$ de largura, originando-se dos conidiomas. Conídios hialinos, oblongos a elipsóides, lisos, verdes em massa, 4,0-5,0 x 2,5-3,0 $\mu \mathrm{m}$. Clamidósporos globosos a subglobosos terminais ou intercalares, cerca de $8 \mu \mathrm{m}$ de diâmetro.

\section{Habitat}

O teleomorfo ocorre em frutos mumificados de cacau e outras esterculiáceas, bem como, em vassouras secas de cacaueiro. Trichoderma stromaticum tem sido isolado da serrapilheira do cacaueiro e também da superfície de folhas vivas da copa do cacaueiro.

Distribuição geográfica - O teleomorfo é conhecido apenas na região cacaueira do estado da Bahia e o anamorfo tem ocorrência também nos estados do Pará e Rondônia.

Holotipo - BRASIL, BAHIA: Município de Ilhéus, Centro de Pesquisa do Cacau, $14^{\circ} 45^{\prime}$ S e $39^{\circ} 13^{\prime}$ W, 03 de junho de 1998, sobre frutos secos de cacau,J.L. Bezerra (HERBÁRIO

TABELA 1 - Matriz de similaridades genéticas entre dois isolados de Trichoderma stromaticum, dois de Hypocrea stromatica e um de Fusarium sp. calculada com base em 73 marcadores RAPD

\begin{tabular}{lccccc}
\hline \hline \multirow{2}{*}{ Espécie Fúngica } & \multicolumn{5}{c}{ Isolados } \\
\cline { 2 - 6 } & $\mathbf{1}$ & $\mathbf{2}$ & $\mathbf{3}$ & $\mathbf{4}$ & $\mathbf{5}$ \\
\hline Trichoderma stromaticum (1) & $1,00^{1}$ & & & & \\
T. stromaticum (2) & 0,96 & 1,00 & & & \\
Hypocrea stromatica (3) & 0,83 & 0,82 & 1,00 & & \\
H. Stromatica (4) & 0,84 & 0,83 & 0,93 & 1,00 & \\
Fusarium sp. (5) & 0,09 & 0,06 & 0,09 & 0,09 & 1,00 \\
\hline
\end{tabular}

${ }^{1}$ Coeficiente de similaridade de Nei \& Li (1979).
CEPEC, 94.140); Micoteca da SEFIT n 3.106, cultura isolada de $H$. stromatica sobre vassouras secas de cacau.

\section{Outros espécimes examinados}

BRASIL, BAHIA: Município de Ilhéus, Centro de Pesquisa do Cacau, 03 de junho de 1998, sobre frutos secos de cupuaçu. J.L. Bezerra (HERBÁRIO CEPEC, 94.137); 03 de junho de 1998, sobre frutos secos de cacau,J.L. Bezerra (HERBÁRIO CEPEC, 94.139); 03 de junho de 1998, sobre frutos secos de cacau-do-peru. J.L. Bezerra (HERBÁRIO CEPEC, 94.138); 09 de julho de 2001, sobre frutos secos de cacau, J.C.B.Costa (HERBÁRIO CEPEC, 94.135). Município de Santo Amaro, ESOMI, $12^{\circ} 33^{\prime}$ S e $38^{\circ} 42^{\prime} \mathrm{W}$, sobre frutos secos de cacau. D.R. Vieira, 20 de agosto de 2002 (HERBÁRIO CEPEC, 94.136), Micoteca da SEFIT no 3.333 e 3.453, culturas isoladas de $H$. stromatica sobre frutos secos de cacau.

\section{DISCUSSÃO}

O gênero Hypocrea é aceito na literatura como o teleomorfo de Trichoderma Pers. Ex Fr. (Chaverri et al., 2001). Estudos culturais comprovam que muitas espécies de Hypocrea produzem a forma conidial (Trichoderma), mas o oposto não é verdadeiro para a maioria das espécies (Gams et al., 1980). A descoberta do teleomorfo de $T$. stromaticum sugere a possibilidade de recombinação sexual favorecendo a variabilidade genética da espécie. Estromas periteciais nunca foram observados em culturas de $T$. stromaticum nem em culturas derivadas de ascósporos, porém, a ocorrência de $H$. stromatica é comum na natureza, nas condições da região cacaueira da Bahia. No momento, não é possível inferir se $H$. stromatica é espécie homotálica ou heterotálica. As culturas conidiais apresentaram variabilidade quanto ao aspecto do micélio, sendo observado durante os isolamentos, variações na compatibilidade vegetativa entre as colônias formadas.

Espécies de Hypocrea, às vezes, só podem ser separadas pelos anamorfos, sendo os respectivos teleomorfos praticamente indistinguíveis (Samuels et al., 1998). Hypocrea stromatica distingue-se das demais espécies congenéricas pelas características únicas do seu anamorfo, que justificaram a criação de uma espécie nova de Trichoderma (Samuels et al., 2000). Kullnig-Gradinger et al. (2002) estudaram a filogenia e a evolução do gênero Trichoderma utilizando o sequenciamento da região ribossomal (18S e $28 \mathrm{~S}$ ) e situaram a espécie $T$. stromaticum, juntamente com um Trichoderma sp. não identificado, em um grupo isolado das demais espécies do gênero.

O uso de marcadores RAPD tem permitido o estudo da diversidade genética inter e intra-específica, caracterização de raças fisiológicas e classificação detalhada de isolados de fungos (Faleiro et al., 1998; 2002; Brioso et al., 2001). Variabilidade genética intra-específica, como a observada entre os isolados de T. stromaticum e H. stromatica, é comumente detectada ao se utilizar marcadores RAPD; entretanto, quando são analisados isolados de espécies diferentes, os valores de distâncias genéticas são muito mais altos, a exemplo dos 
Hypocrea stromatica sp. nov. teleomorfo de Trichoderma stromaticum

Distância Genética Relativa (\%)

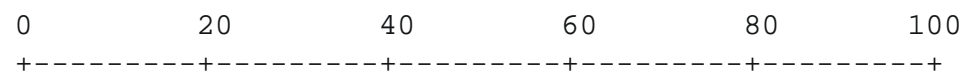

Trichoderma stromaticum (1)

$$
\begin{array}{r}
\text { T. stromaticum (2) } \\
\text { Hypocrea stromatica (3) } \\
\text { H. stromatica (4) } \\
\text { Fusarium sp. (5) }
\end{array}
$$

FIG. 1 - Análise de agrupamento de dois isolados de Trichoderma stromaticum, dois de Hypocrea stromatica e um de Fusarium sp. baseada na matriz de distâncias genéticas, pelo método do centróide.

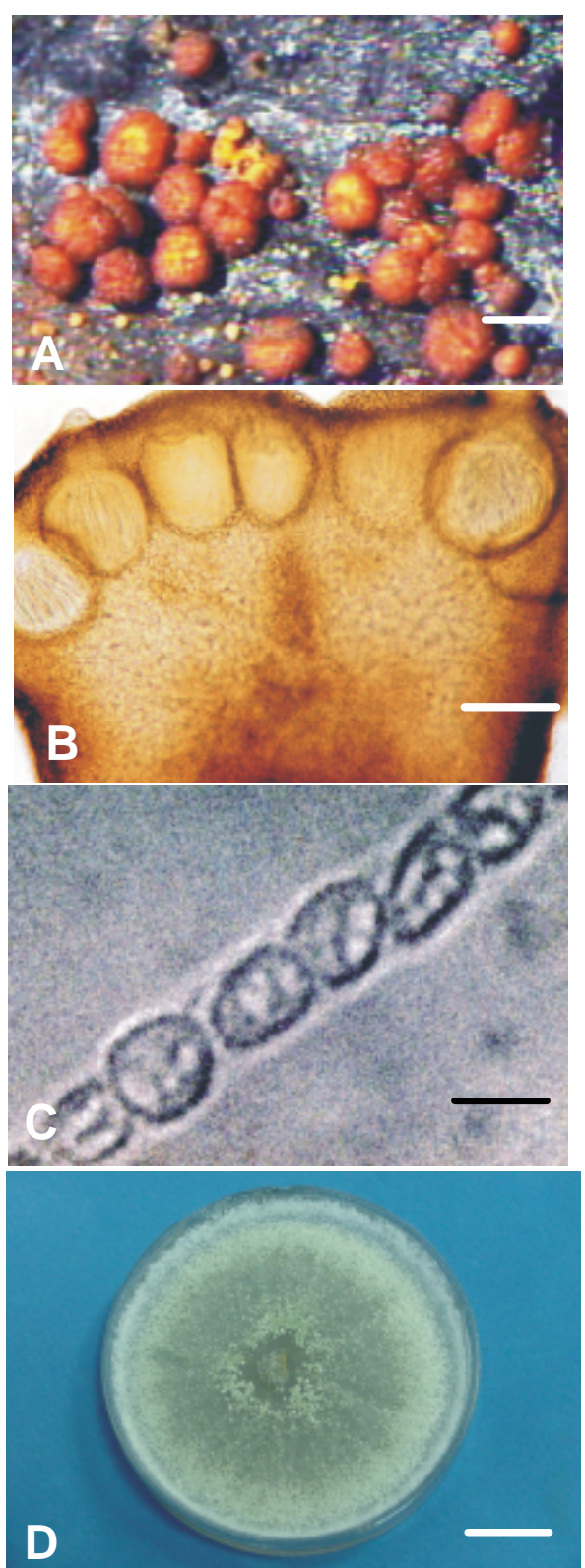

FIG. 2 - Hypocrea stromatica. A. Vista frontal dos estromas; B. Corte longitudinal de um estroma mostrando peritécios e ostíolos (setas); C. Segmento de um asco com ascósporos unisseriados; D. Cultura do anamorfo, Trichoderma stromaticum, originária da germinação de ascósporos. Barras: $1=0,8 \mathrm{~mm} ; 2=120 \mu \mathrm{m} ; 3=5 \mu \mathrm{m}$; e $4=2 \mathrm{~mm}$. observados entre tais isolados e aqueles do gênero Fusarium. As diferenças genéticas entre isolados de $T$. stromaticum e $H$. stromatica foram muito inferiores às observadas entre tais isolados e os de Fusarium sp. (Tabela 1). A análise de agrupamento dos isolados (Figura 1) ilustra tal observação e mostra a similaridade genética entre os isolados de $T$. stromaticum e H. stromatica.

Com base nos dados morfobiométricos, juntamente com os marcadores moleculares, fica evidente a conexão entre o anamorfo ( $T$. stromaticum) e o teleomorfo (H. stromatica) subsidiando a descrição da nova espécie e elucidando o ciclo vital deste fungo.

\section{AGRADECIMENTOS}

Aos estagiários Kátia Maria Trindade Bezerra, Patrícia Valéria Santos Menezes e Eusimar Junes dos Santos Filho pela ajuda nos isolamentos e trabalhos laboratoriais. Aos colegas Alfredo Dantas Neto e Alessandra S. G. Faleiro pelo apoio na execução das técnicas moleculares e Edna Dora Martins Newman Luz, Stela Dalva Vieira Midlej Silva e Karina Peres Gramacho, pela leitura do manuscrito e valiosas sugestões.

\section{REFERÊNCIAS BIBLIOGRÁFICAS}

BRIOSO, P.S.T., POZZER, L., MONTANO, H.G. \& PIMENTEL, J.P. Uso atual e futuro da biologia molecular na fitopatologia. Parte I - Aplicações em fitopatógenos e vetores. Revisão Anual de Patologia de Plantas 9:7-118. 2001.

CHAVERRI, P., SAMUELS, G.J. \& STEWART, E.L.. Convergent evolution of Gliocladium morphology in Hypocrea. Abstract. Inoculum. Newsletter of the Mycological Society of America. Mycologia 51:24. 2000. (Abstract)

CHAVERRI, P., SAMUELS, GJ. \& STEWART, E.L. Hypocrea virens sp. nov., the teleomorph of Trichoderma virens. Mycologia 93:1113-1124. 2001.

COSTA, J.C.B. \& BASTOS, C.N. Controle biológico da vassourade-bruxa. Anais. Reunião de Controle Biológico de Fitopatógenos, 2001. pp.45-51.

CRUZ, C.D. Programa Genes: aplicativo computacional em genética e estatística. Viçosa, MG, UFV. 1997.

FALEIRO, F.G., RAGAGNIN, V.A., MESQUITA, A.G.G., VINHADELLI, W.S., PAULA JR., T.J., MOREIRA, M.A. \& 


\section{J.L. Bezerra et al.}

BARROS, E.G. Diversidade genética de isolados de Uromyces appendiculatus, com a utilização de marcadores moleculares RAPD. Fitopatologia Brasileira 23:386-390. 1998.

FALEIRO, F.G., LUZ, E.D.M.N., CERQUEIRA, A.O. \& ROCHA, C.S.S. Uso de marcadores RAPD como ferramenta auxiliar na classificação de isolados de Phytophthora spp. causadores da podridão parda do cacaueiro no Brasil. Fitopatologia Brasileira. 27:241. 2002. (Resumo)

GAMS, W., DOMSCH, K.H. \& TRAUTE-HEIDI, A. Compendium of soil fungi. London, Academic Press. V.1 p.794. 1980.

KULLNIG-GRADINGER, C.M., SZAKACS, G. \& KUBICEK, C.P. Phylogeny and evolution of the gems Trichoderma: a multigene approach. Mycological Research 106:757-767.2002.
NEI, M. \& Li, W.H.. Mathematical model for studying genetic variation in terms of restriction endonucleases. Proceedings of the National Academy of Sciences USA 76:5269-5273. 1979.

SAMBROOK, J., FRITSCH, E.F. \& MANIATIS, T. Molecular cloning: a laboratory manual. New York, Cold Spring Harbor Laboratory Press, Cold Spring Harbor, v.3. 1989.

SAMUELS, G.J., PARDO-SCHULTHEISS, R., HEBBAR, K.P., LUMSDEN, R.D., BASTOS, C.N., COSTA, J.C.B. \& BEZERRA, J.L.. Trichoderma stromaticum sp. nov., a parasite of the cacao witches broom pathogen. Mycological Research 104:760-764. 2000.

SAMUELS, G.J., PETRINI, O., KUHLS, K., LIECKFELDT, E. \& KUBICEK, C. The Hypocrea schweinitzii complex and Trichoderma sect. Longibrachiatum. Studies in Mycology 41:1-54. 1998. 